\title{
Sexual Orientation
}

National Cancer Institute

\section{Source}

National Cancer Institute. Sexual Orientation. NCI Thesaurus. Code C84361.

The pattern of a person's emotional, romantic, and/or sexual attractions. 